\title{
LA DEMOCRACIA DIRECTA Y LA DEMOCRACIA PARTICIPATIVA HOY: DE SUIZA A LA A. LATINA DEL SOCIALISMO DEL SIGLO XXI
}

Sirio López Velasco ${ }^{1}$

\section{Resumen}

En este trabajo nos proponemos resumir brevemente la experiencia suiza en materia de democracia directa o de democracia participativa (desde la Constitución aprobada en 1848) y presentar las formas que esas dos variantes democráticas (junto y paralelamente a ciertas instancias de democracia representativa) vienen asumiendo en los tres países latinoamericanos que han levantado la bandera del "socialismo del siglo XXI), a saber, Venezuela, Bolivia y Ecuador.

Palabras-clave: Democracia Directa. Democracia Participativa. Suiza. Socialismo Del Siglo XXI, A. Latina.

\section{DIRECT DEMOCRACY AND PARTICIPATIVE DEMOCRACY TODAY: FROM SWITZERLAND TO LATIN AMERICA OF THE XXI ${ }^{\text {th }}$ CENTURY SOCIALISM}

\begin{abstract}
:
In this paper we shall make a short synopsis on direct and participative democracy in Switzerland (since the Constitution of 1848) and present the characteristics of these forms of democracy in the Latin American countrys who have reclaimed the principles of "the XXI ${ }^{\text {th }}$ century socialism", namely Venezuela, Bolivia and Ecuador.
\end{abstract}

Key words: Direct Democracy. Participative Democracy. Switzerland. XXI ${ }^{\text {th }}$ Century Socialism, Latin America.

\section{Introducción}

Entendemos por democracia directa aquella (ejemplarizada en la Atenas clásica) en la que los ciudadanos deciden directamente y sin intermediarios los asuntos del Estado, desde lo local hasta las directrices de política internacional. En la actualidad se citan como ejempl/os de su funcionamiento algunas formas del sistema político suizo y del llamado Nuevo Constitucionalismo Latinoamericano (NCL, en especial en Venezuela, Bolivia y Ecuador). Son mecanismos principales de la democracia directa el

\footnotetext{
${ }^{1}$ Possui graduação em Filosofia - Universite Catholique de Louvain (1981), graduação em Lingüística Universite Catholique de Louvain (1983) e doutorado em Filosofia - Universite Catholique de Louvain (1985). Pós-doutorado em Ética no Instituto de Filosofía do Consejo Superior de Investigaciones Ciéntíficas (Madrid, España, 2002). Atualmente é professor titular da Fundação Universidade Federal do Rio Grande onde atúa no Doutorado e Mestrado em Educação Ambiental. Tem experiência na área de Filosofia e Educação Ambiental, com ênfase em Ética Argumentativa, atuando principalmente nos seguintes temas: educacao ambiental, ética argumentativa, ecomunitarismo, e ética da libertacao. E-mail: lopesirio@hotmail.com.
} 
voto en asambleas, los plebiscitos y los referendos (en un plebiscito los ciudadanos deciden sobre algo todavía no recogido en una ley, mientras que los referendos se convocan para decidir sobre una norma o decisión ya tomada por alguna instancia del poder institucional representativo establecido).

A su vez las instancias de democracia participativa son aquellas en las que, dándose por supuesta y predominante una (supuesta) democracia representativa, los ciudadanos disponen de mecanismos concretos para, sobre la marcha, controlar-corregir a sus supuestos representantes o instituciones, y para sugerirles normas o acciones. También destacan aquí los ejemplos de Suiza y del NCL. Son mecanismos principales de tal democracia los referendos para ratificar o revocar a autoridades previamente elegidas, el dispositivo de iniciativa popular para la tramitación de nuevas leyes, y las instancias consultivas (en las que el ciudadano es oído, o es consultado, o puede emitir quejas y sugerencias, sin, no obstante, poseer el poder de la decisión final a través de su voto).

\section{La democracia directa y la democracia participativa en Suiza}

En lo que sigue nos basaremos ampliamente en los datos y referencias proporcionados por Emmanuel Daniel (2012). Suiza tiene cerca de 8 millones de habitantes y 5 millones de electores. Es una República Federal estructurada en base a 26 Cantones, cada uno de los cuales tiene su propia Constitución. Cada cantón incluye diversas comunas.

Ahora, los ciudadanos eligen una Asamblea Federal, compuesta de dos Cámaras (la de los Estados, y el Consejo Nacional) con poderes iguales. El Gobierno, llamado Consejo Federal está compuesto de 7 miembros e integra a los Partidos más votados, lo que se traduce en el hecho de que no existe una oposicioón partidaria con gran fuerza electoral. (Hay que recordar que entre 1952 y 1967 el Uruguay conoció por varios períodos de gobierno un Ejecutivo constituído por un Consejo Nacional de Gobierno integrado por miembros del Partido con mayor votación, y miembros del segundo, por lo que en ese lapso el Ejecutivo estuvo integrado por miembros pertenecientes al Partido Nacional-Blanco, y del Partido Colorado, con exclusión de toda la izquierda de la época; esa representación también se extendió a la dirección de los Entes públicos, como las compañías de electricidad y agua, entre otras; dada la corrupción e ineficacia que ese sistema evidenció, en 1966 una reforma constitucional aprobada en referendo volvió al Ejecutivo unipersonal ejercido por un Presidente de la República). En Suiza el

\begin{tabular}{|l|l|l|l|l|}
\hline Qevista Dialectus & Ano 4 & n. 10 & Janeiro - Julho 2017 & p. 10-23 \\
\hline
\end{tabular}


Presidente del Consejo es una figura articuladora, con un poder limitado por el Consejo Federal al que está subordinado. Toda reforma constitucional exige una doble mayoría, a saber la mayoría de los electores a nivel nacional, y la aprobación mayoritaria en la mayoría de los 26 Cantones (o sea, en, por lo menos, 14); lo mismo se exige para las decisiones relativas a la adhesión a organismos internacionales. En ambos casos los referendos son obligatorios, y desde la Constitución de 1848 hasta 2012 hubo 214 referendos de ese tipo. Entre las formas directas de la democracia, Suiza incorpora también los referendos facultativos que pueden anular una ley aprobada en los 100 dias anteriores; para convocarlos son necesarias las firmas de 50 mil electores; desde 1848 y hasta 2012, en 169 convocaciones, 93 leyes fueron anuladas. (No obstante, Sprich, 2017, nota que "tan sólo 6\% de las leyes fueron objeto de tal oposición", pero no queda claro a cuál período de tiempo se refiere, ni tampoco si habla del porcentaje de leyes anuladas efectivamente mediante referendo, o del total de leyes sometidas a referendo).

Desde 1848 hasta 2012 hubo en Suiza, en total, 565 referendos.

Por su parte, la iniciativa legislativa, forma de la democracia participativa, puede ser activada por las firmas de 100 mil electores (recogidas en hasta 18 meses). Recientemente una iniciativa de ese tipo y que logró tal número de firmas, surgió de un campesino que propuso proteger a los animales con cuernos (en especial toros y vacas) en su derecho a conservar dichos cuernos (Sprich, 2017).

Los mismos mecanismos se reproducen, en escala reducida, en los niveles cantonal y comunal. Todas las leyes aprobadas por un Parlamento cantonal deben ser sometidas al voto de sus electores. A su vez, en el sistema llamado ordinario, los ciudadanos de una Comuna se reúnen en asamblea para tomar las decisiones; mas existe el llamado sistema extraordinario, cuando hay un Parlamento comunal (Daniel, 2012).

Los suizos condensan en 4 días por año el conjunto de las votaciones para las que son solicitados. Para los referendos pueden recibir las papeletas en su casa, y devolverlas, con su voto, vía postal. (Nótese que nuevas perspectivas se abren con la posibilidad del voto vía internet).

Entre los asuntos que han debatido-decidido a nivel federal se encuenttran temas tan relevantes como el sistema de pensiones (que sigue siendo una cuestión que penaliza repetidamente a los ciudadanos en países donde la misma no se somete a la consideración de la ciudadanía), el derecho a gozar de dos semanas suplementarias de vacaciones anuales (posibilidad que los suizos terrminaron negando con su voto!), el

\begin{tabular}{|l|l|l|l|l|}
\hline Qevista Dialectus & Ano 4 & n. 10 & Janeiro - Julho 2017 & p. 10-23 \\
\hline
\end{tabular}


derecho a una renta básica (rechazado en 2016 por casi el 77\% de los votantes; Sprich 2017), y la laicidad. Entre los asuntos locales se pueden mencionar el sistema de recolección de residuos y la construción de residencias secundarias en áreas protegidas.

Otros temas deliberados-decididos por los ciudadanos de forma directa desde 1891 fueron asuntos relativos a derechos del trabajo y jornada laboral, impuesto sobre la riqueza, medidas contra la especulación, protección de los inquilinos, lucha contra el absinto, el alcoholismo y el tabaquismo, construcción de casas populares, limitación del secreto bancario, política de transportes públicos, limitación de la velocidad en las carreteras y disminución del tránsito carretero, control de precios, cuestiones de salud pública, prohibición de las casas de juego de azar, prohibición de los transgénicos en la agricultura, y cuestiones ambientales (anónimo, 2013).

\section{Críticas a la democracia suiza y algunas respuestas}

Ahora bien, en los últimos años los suizos (por iniciativa de la derecha, en especial la del Partido UDC, Union Démocratique du Centre) han deliberado-votado también sobre la prohibición de los minaretes de las mezquitas (en circunstancias en las que en todo el país apenas había cuatro de ellos! ) y sobre la expulsión de criminales de origen extranjero (propuesta rechazada masivamente en 2016; Sprich, 2017). Estas votaciones sumadas a las que anteriormente citamos hacen decir a una pluma expresamente identificada con el "pensamiento liberal" que la democracia directa suiza refuerza al Estado en detrimento de las libertades individuales, por lo que la reprueba (2013). Otro autor, defensor de esa democracia, recuerda que las tendencias xenófobas siempre la habitaron, porque ya en 1848 se prohibió a los judíos trabajar en la administración federal; y en materia de intolerancia religiosa recuerda que se prohibieron a los católicos los campanarios de iglesias en los cantones protestantes. Pero al mismo tiempo recuerda que desde 1970 sólo el 6\% de las votaciones federales estuvo dedicado a cuestiones de seguridad, mientras que las relativas a cuestiones sociales y ambientales ocuparon, respectivamente, el 23 y el $21 \%$ de las consultas (2012).

También dice nuestro mismo anónimo (2013) que la participación ciudadana en Suiza fue cayendo progresivamente a lo largo del siglo XX, pues si en su inicio alcanzaba el $70 \%$, a su fin no superaba el $30 \%$ del cuerpo electoral. No obstante había notado Daniel (2012) que la participación oscila en función de la trascendencia del tema sometido a voto, alcanzando una media del $45 \%$ en la primera década del siglo XXI,

\begin{tabular}{|l|l|l|l|l|}
\hline Q Povista Dialectus & Ano 4 & n. 10 & Janeiro - Julho 2017 & p. 10-23 \\
\hline
\end{tabular}


con picos del 80\%, y que, además, hay un efecto de auto-censura del ciudadano cuando no se considera suficientemente conocedor o informado sobre el tema en debate, por lo que se abstiene de votar.

Daniel (2012) también sostiene que en el sistema suizo "Los parlamentarios, aunque su salario aumentó significativamente en los últimos años, no son, en teoría, profesionales de la política. La división del poder con el pueblo los empuja a una mayor transparencia y proximidad. Eso se verifica en especial en la redacción de los textos de las leyes, que deben ser cortos e inteligibles para la mayoría de la población”.

Y, sopesando todos los aspectos citados, concluye: “....no hay dudas de que Suiza es actualmente en Europa la democracia- 'el gobierno del pueblo, por el pueblo y para el pueblo', según la expresión de Lincoln- más avanzada, en términos de soberanía popular y de implicación de los ciudadanos en las tomas de decisión. En suma, es lo que tenemos derecho a esperar en una democracia".

\section{La democracia directa o participativa en la A. Latina del socialismo del siglo XXI}

Como vimos en la conclusión recién citada de Daniel, su reflexión acerca de la democracia (ejemplificada en Suiza) acepta sin discusión los límites del capitalismo (aunque éste sea suavizado por medidas de protección social y/o de caracter ambiental). Ahora bien, desde A. Latina se ha levantado en el siglo XXI una propuesta (todavía en plena elaboración) que pretende re-pensar la democracia en función del socialismo (también repensado a la luz del presente siglo); tal propuesta ha germinado en Venezuela, Bolivia y Ecuador (países cuyos respectivos gobiernos dijeron abrazar la causa del "socialismo del siglo XXI"), e inspira reflexiones acerca del sistema político implantado en Cuba desde la Revolución, buscando corregir-mejorar su apuesta socialista.

El socialismo del siglo XXI arranca en América Latina con una reforma constitucional impulsada por el Presidente recién electo, Hugo Chávez, aprobada en 1999 que se presentó como una refundación de la nación venezolana (que incluso cambió el nombre del país que pasó de "República de Venezuela" a "República Bolivariana de Venezuela") prometiendo una "democracia participativa y protagónica", para superar la democracia representativa ; pero Chávez proclamó explícitamente el "socialismo del siglo XXI" como idea rectora de la revolución bolivariana sólo en 2005; esa idea se mantiene vinculada al debate acerca de aquella Constitución, en especial en el referendo constitucional realizado el 2 de diciembre de 2007 (en el que la propuesta

\begin{tabular}{|l|l|l|l|l|}
\hline Q Povista Dialectus & Ano 4 & n. 10 & Janeiro - Julho 2017 & p. 10-23 \\
\hline
\end{tabular}


de reforma defendida por Chávez fue derrotada), en el referendo sobre la enmienda que facultaba la postulación del Presidente a reelecciones continuadas y sin límites, de febrero de 2009 (en el que la propuesta de Chávez fue aprobada), y en el proceso de nueva Asamblea Nacional Constituyente (ANC) que se abre con su convocación por el Presidente Maduro el 1 de mayo de 2017. Ese proceso se abre en momentos en los que la derecha venezolana se lanzó a una verdadera insurrección no declarada (con repetidos y cotidianos actos violentos en las calles y contra edificios públicos, incluyendo escuelas y hospitales), exigiendo la derrocada inmediata de Maduro, si fuera preciso con la intervención militar de sus apoyadores (en especial el gobierno de los EEUU y algunos países de la OEA), y el llamado inmediato a elecciones presidenciales (previstas por la Constitución vigente sólo para diciembre de 2018). Al mismo tiempo desde el gobierno venezolano se ha convocado finalmente a las elecciones para Gobernadores (que deberían haber sido realizadas en 2016 y lo serán en diciembre de 2017) y ha ratificado que las elecciones presidenciales tendrán lugar a fines de 2018. Ahora bien, interesa destacar aquí que el actual proceso constituyente combina rasgos de democracia directa, participativa y representativa. Así pertenece a la democracia directa la posibilidad abierta a cualquier ciudadano de postularse para ser uno de los 545 constituyentes en la elección prevista para el 30 de julio de 2017 (más de 50 mil se inscribieron, pero cada postulante tendrá que contar con el respaldo de las firmas del $3 \%$ de los electores para hacer efectiva su candidatura el día de la elección), la posibilidad dada a los pueblos indígenas para que elijan 8 constituyentes "de acuerdo a sus costumbres y prácticas ancestrales" (según los artículos 119 y 125 de la Constitución en vigor), y el referendo al que será sometida finalmente la nueva Constitución que se elabore (según quedó establecido en la solicitación hecha a la futura ANC en la ampliación de sus bases comiciales, entregada por el Gobierno al Consejo Nacional Electoral a principios de junio de 2017). La democracia participativa se dará en los innúmeros debates y sugerencias populares que serán recogidas antes y durante las sesciones de la ANC. Y la democracia representativa se expresará a través de la elección de los constituyentes en voto universal, directo y secreto. Los constituyentes, además de los indígenas, serán electos simultáneamente mediante los criterios territorial y sectorial; así, habrá representantes de cada uno de los Municipios del país, y también de diversos sectores como lo es el de los trtabajadores y estudiantes (además de los pescadores, discapacitados y otros). Los indígenas elegirán a sus constituyentes en tres

\begin{tabular}{|l|l|l|l|l|}
\hline Qevista Dialectus & Ano 4 & n. 10 & Janeiro - Julho 2017 & p. 10-23 \\
\hline
\end{tabular}


regiones, y se calcula que más de 3.500 asambleas ocurrirán hasta llegar a la designación de sus 8 representantes. El sector de los trabajadores (dividido en 9 subsectores, que abarcan, entre otros, el subsector de la construcción, del petróleo, de los transportes, del comercio, de los servicios y los trabajadores independientes) elegirá a 79 constituyentes; también serán electos representantes de las Comunas (hay que recordar que en cada barrio o localidad puede haber más de un Consejo Comunal y que los mismos se nuclean en Comunas, donde se debaten los proyectos de los vecinos para el barrio o la localidad, recibiendo, si todo va bien, del Gobierno municipal, estadal y/o central, los recursos necesarios para implementarlos, trátese de una pequeña fábrica cooperativa o de una plaza de deportes, entre otras posibilidades, con las fiscalizaciones necesarias para garantizar un honesto y eficiente uso de los recursos recibidos). A su vez, los estudiantes elegirán a 24 constituyentes (universitarios y eventualmente alguno de la enseñanza media). Cada elector ejercerá simultáneamente (si lo desea) un doble voto, a saber, uno para el nivel territorial (de su Municipio) y otro para su sector de actividad.

Hay que notar que, a menos que renuncien a sus cargos, no podrán candidatarse a constituyente el Presidente y el Vice-Presidente de la República, los Ministros, los Gobernadores, los Secretarios de Estado, los Diputados, los Consejales, los Magistrados, los Presidentes de Institutos Autónomos, y tampoco el Fiscal General ni el Defensor del Pueblo.

Los objetivos que el Presidente Maduro postula para la ANC y la nueva Constitución son: 1. Ganar la paz nacional, 2. Ampliación del sistema económico, 3. Constitucionalizar las misiones sociales, 4. Fortalecimiento del Sistema de Justicia, 5. Consagrar nuevas formas de la Democracia Participativa y Protagónica, 6. Defensa de la soberanía, 7. Profundizar en la identidad Cultural, 8. Garantizar el Futuro de la Juventud, y, 9. La preservación de la vida en el planeta.

Dada la actual correlación de fuerzas (en la que los Partidos de derecha que son mayoría en la actual Asamblea Nacional se han negado a participar de la ANC), mucha gente se pregunta si la Constitución resultante de la ANC logrará ser aprobada en el referendo final. Por nuestra parte también nos preguntamos acerca de algunas de las propuestas que las fuerzas bolivarianas podrán o no llevar a la ANC, por ejemplo, si aceptarán mantener o no el control que la oligarquía venezolana tiene actualmente sobre grandes medios de producción, distribución y financieros del país (incluyendo

\begin{tabular}{|l|l|l|l|l|}
\hline Qevista Dialectus & Ano 4 & n. 10 & Janeiro - Julho 2017 & p. 10-23 \\
\hline
\end{tabular}


latifundios, grandes empresas y bancos), sobre grandes medios de comunicación impresos y/o audiovisuales, y sobre parte del pluripartidismo ahora existente. Consideramos que de la respuesta a tales cuestiones vitales dependerán los avances reales más importantes rumbo a la superación del capitalismo en perspectiva socialista (que, por nuestra parte, queremos también con horizonte ecomunitarista), dando por sentado que para ello los bolivarianos mantendrán la unión cívico-militar que les garantiza hasta ahora el control casi total de las Fuerzas Armadas y las Milicias Populares del país (ancla blindada de cualquier proceso soberano). En ese contexto también se da por hecho la manutención y ampliación de importantes mecanismos de democracia directa, como lo son los referendos (incluyendo los revocatorios de autoridades previamente electas, incluyendo al propio Presidente de la República, como el que tuvo que enfrentar una vez Chávez, saliendo vencedor), al tiempo que se pueden incorporar plebiscitos nacionales, estadales, municipales y aun comunales, $\mathrm{y}$ mecanismos de decisión asambleística, como los existentes en algunas Comunas suizas. Todo ello en función de resolver carencias serias en la alimentación sana y la salud de la mayoría del pueblo venezolano, que en la actualidad no logra acceder a bienes y servicios básicos de esas áreas por falta o escacez, y/o por sus altos precios en un proceso inflacionario de grandes proporciones.

Por otro lado, Bolivia también pretende reconstituir las bases mismas de la convivencia social y con la naturaleza no humana a través de una reforma constitucional aprobada en referendo en enero de 2009.

La nueva Constitución boliviana en su art. 11 dice "El Estado adopta para su gobierno la forma democrática, participativa, representativa y comunitaria, con equivalencia de condiciones entre hombres y mujeres"; y aclara: "La democracia se ejerce de las siguientes formas, que serán desarrolladas por la ley: 1) directa y participativa, por medio del referendo, la iniciativa legislativa ciudadana, la revocatoria del mandato, la asamblea, el cabildo y la consulta previa, entre otros; las asambleas y cabildos tendrán carácter deliberativo, 2) representativa, por medio de la elección de representantes por voto universal, directo y secreto, entre otros, 3) comunitaria, por medio de la elección, designación o nominación de autoridades y representantes por normas y procedimientos propios de las naciones y pueblos indígena originario campesinos, entre otros" (los subrayados son míos, y como se ve, el tercer punto refiere a la perspectiva intercultural del socialismo del siglo XXI, en especial en

\begin{tabular}{|l|l|l|l|l|}
\hline Qevista Dialectus & Ano 4 & n. 10 & Janeiro - Julho 2017 & p. 10-23 \\
\hline
\end{tabular}


A. Latina, de la que me ocuparé de inmediato). El art. 27 extiende el derecho a voto a todas y todos las/los bolivianas y bolivianos residentes en el exterior. Y, si la exclusión del extranjero es una limitación que afectaba ya a la democracia griega de la época clásica, hay que hacer notar que en el caso de Bolivia el derecho de elector se confiere (art. 27) en las elecciones municipales también al extranjero afincado (cosa que sólo algunos países de la Unión Europea comenzaron a practicar recién a fines de los años 80 del siglo XX).

En materia de interculturalidad, hoy resulta claro, especialmente en el caso de A. Latina, que el socialismo del siglo XXI no podrá fundarse únicamente en fuentes occidentales, sino que deberá incorporar dialógicamente las contribuciones positivas oriundas de otras fuentes (particularmente las indígenas y negras). Las culturas indígena y negra han resistido a 500 años de Conquista para legarnos su lúcida perspectiva cosmocéntrica socioambiental. Ello no significa que la unión de esas diversas tradiciones no tenga nudos de difícil manejo, que la filosofía ecomunitarista deberá enfrentar con franqueza (como es el caso, por ejemplo, del machismo que reina también en muchas culturas indígenas y negras). Ahora, la nueva Constitución de Bolivia (fruto de la ingente y a veces violenta movilización indígena-campesina- popular que llevó a Evo Morales al gobierno) va más allá aún que la ecuatoriana y la venezolana en la perspectiva intercultural cuando ya en su Preámbulo entre otras cosas se plantea el reto de "construir colectivamente el Estado Unitario Social de Derecho Plurinacional Comunitario..."; y en el artículo 1 proclama que "Bolivia se constituye en un Estado Unitario Social de Derecho Plurinacional Comunitario, libre, independiente, soberano, democrático, intercultural, descentralizado y con autonomías..." (las cursivas son mías). Expresión concreta de la interculturalidad es la proclamación en el art. 5 de todas las lenguas indígenas ( $¡$ y el texto constitucional enumera nada menos que treinta y seis!) como lenguas co-oficiales del Estado, junto al castellano; más adelante se establece la obligación de que, junto al castellano, por lo menos una lengua indígena sea obligatoria, en función de la diversidad lingüística reinante, en cada región/localidad; y para reforzar esa exigencia, se establece la educación obligatoria bilingüe (también adaptada a la realidad lingüística de cada localidad). Los derechos concedidos a los "pueblos indígena originario campesinos" son descritos en detalles (en especial en el capítulo IV del Título II).

\begin{tabular}{|l|l|l|l|l|}
\hline Q Povista Dialectus & Ano 4 & n. 10 & Janeiro - Julho 2017 & p. 10-23 \\
\hline
\end{tabular}


Dicho todo esto, no son pocos los luchadores, movimientos sociales e incluso partes del movimiento indígena boliviano que consideran hoy que Evo Morales no ha sido consecuente con la letra de la Constitución, y por eso le hacen oposición sistemática $\mathrm{u}$ ocasional (en especial en lo relativo a proyectos económicos gubernamentales que benefician al gran capital, y/o que desconocen la autonomía indígena, y/o que provocan serios daños ambientales). Morales fue derrotado en el referendo en el que postulaba la posibilidad de ser reelecto de manera ilimitada.

A su vez Ecuador adoptó una nueva Constitución en referendo celebrado en setiembre de 2008. Posteriormente el entonces Presidente, Rafael Correa, proclamó el "socialismo del siglo XXI" como meta de su "revolución ciudadana".

Ecuador se propone incentivar la democracia participativa en varios pasajes de esa nueva Constitución; veamos sólo algunos; en el art. 1, se establece que "La soberanía radica en el pueblo, cuya voluntad es el fundamento de la autoridad, y se ejerce a través de los órganos del poder público y de las formas de participación directa previstas en la Constitución" (las cursivas son mías). Su artículo 61 establece que las y los ecuatorianos tienen (entre otros) los siguientes derechos: "a elegir y ser elegidos, participar en los asuntos públicos, presentar proyectos de iniciativa popular normativa, ser consultados, fiscalizar los actos del poder público”... y a conformar partidos y movimientos políticos, afiliarse y desafiliarse libremente de ellos y participar en todas las decisiones que éstos adopten"; y el mismo artículo estipula un mecanismo de democracia directa al conceder a los ciudadanos la posibilidad de "revocar el mandato que hayan conferido a las autoridades de elección popular". A su vez en su art. 57, establece entre otros derechos de las comunidades y de los pueblos indígenas los de "mantener y fortalecer libremente su identidad, sentido de pertenencia, tradiciones ancestrales y formas de organización social", "la consulta previa libre e informada, dentro de un plazo razonable, sobre planes y programas de prospección, explotación y comercialización de recursos no renovables que se encuentren en sus tierras...la consulta que deban realizar las autoridades competentes será obligatoria y oportuna" (aunque se aclara que si hay respuesta negativa se procederá según la Constitución y la ley), “conservar y desarrollar sus propias formas de convivencia y de organización social, y de generación y ejercicio de la autoridad, en sus territorios legalmente reconocidos y tierras comunitarias de posesión ancestral", "crear, desarrollar, aplicar y practicar su derecho propio o consuetudinario" (aunque se aclara que el mismo no podrá

\begin{tabular}{|l|l|l|l|l|}
\hline Q Povista Dialectus & Ano 4 & n. 10 & Janeiro - Julho 2017 & p. 10-23 \\
\hline
\end{tabular}


violar preceptos constitucionales, en especial en lo que se refiere a mujeres, niños y adolescentes), “desarrollar, fortalecer y potenciar el sistema de educación intercultural bilingüe...desde la estimulación temprana hasta el nivel superior...", "construir y mantener organizaciones que los representen [a los pueblos indígenas]... [y] el Estado reconocerá y promoverá todas sus formas de expresión y organización”, “participar a través de sus representantes en los organismos oficiales que determine la ley, en la definición de las políticas públicas que les conciernen, así como en el diseño y decisión de sus prioridades en los planes y proyectos del Estado", "ser consultados antes de la adopción de una medida legislativa que pueda afectar cualquiera de sus derechos colectivos", y concluye exigiendo "que la dignidad y diversidad de sus culturas, tradiciones, historias y aspiraciones se reflejen en la educación pública y en los medios de comunicación; la creación de sus propios medios de comunicación y el acceso a los demás sin discriminación alguna".

Al mismo tiempo en el área socioambiental la nueva Constitución ecuatoriana dice ya en su preámbulo: "Nosotras y nosotros, el pueblo soberano del Ecuador... celebrando a la naturaleza, la Pacha Mama de la que somos parte y que es vital para nuestra existencia...decidimos construir una nueva forma de convivencia ciudadana, en diversidad y armonía con la naturaleza, para alcanzar el buen vivir, el sumak kawsay"; y todo el capítulo 2 del Título VII está dedicado a la biodiversidad y los recursos naturales (incluyendo las siguientes secciones: naturaleza y ambiente, biodiversidad, patrimonio natural y ecosistemas, recursos naturales, suelo, agua, biosfera, ecología urbana y energías alternativas).

Ahora, transcurridos diez años de la presidencia de Correa, en abril de 2017 su sucesor logró imponerse a un contendor banquero y claramente neoliberal (muy conocido por los ecuatorianos) por tan sólo un $2 \%$ de diferencia en la segunda vuelta de la elección presidencial. Ello obliga a repensar falencias de la experiencia ecuatoriana que, apoyándonos en François Houtart, ya reseñamos en otro trabajo (López Velasco 2016), y de las que podríamos destacar aquí, por ejemplo, la arrogancia personal de Correa ante fuerzas indígenas y/o populares y/o de supuesta izquierda que no lo apoyaran incondicionalmente, sus manifiestas contradicciones filosóficosocioambientales-interculturales al intentar realizar efectivamente un "capitalismo moderno" (en vez del "socialismo del siglo XXI" que decía defender), sin olvidar las denuncias de corupción que pesaron sobre algunos funcionarios. Las primeras palabras

\begin{tabular}{|l|l|l|l|l|}
\hline Qevista Dialectus & Ano 4 & n. 10 & Janeiro - Julho 2017 & p. 10-23 \\
\hline
\end{tabular}


del sucesor de Correa parecen augurar un Gobierno aún más conciliador con la oligarquía y burguesía ecuatorianas y quizá incluso con el imperio yanqui-OTAN y ese ministerio de colonias de los EEUU (como lo llamó el Che) que es la OEA.

Por último, hay que notar que un cubano revolucionario insinúa que su país podría inspirarse del Nuevo Constitucionalismo Latinoamericano para perfeccionar la democracia socialista cuando dice: "El NCL reconoce el derecho a participar en la elaboración, ejecución y control de los presupuestos del Estado, a exigir audiencias, veedurías, consultas previas, cabildos abiertos, consejos consultivos y observatorios, y regula figuras como la 'silla vacía', admite todas las formas de organización de la sociedad, instituye el Poder Ciudadano o el Consejo de participación ciudadana, y dicta leyes regulatorias de los derechos de participación, exigibles en cuanto derechos, aun cuando no hayan sido dictadas las leyes que regulen su ejercicio; prevé la iniciativa popular, legislativa y constitucional o el referendo aprobatorio, consultivo, revocatorio y abrogatorio y reglamenta vías ágiles de acceso a los tribunales, la participación directa del pueblo en la designación de jueces, la posibilidad de formulación directa de objeciones a la postulación de candidatos a magistrados del Tribunal Supremo de Justicia y la elección de jueces del Tribunal Constitucional” (Guanche, p. 4). También nota Guanche (p. 14) que fuera del sistema político-electoral como tal, en Cuba muchos cargos estatales son nombrados o designados; ello sucede con los Rectores de las Universidades; a ese respecto reivindicamos en la construcción de una democracia orientada hacia el socialismo ecomunitarista la ley uruguaya de Autonomía Universitaria que desde 1958 atribuye esa potestad a la propia comunidad universitaria (aunque excluyendo inicialmente a los funcionarios, para confiarles el poder decisorio a los docentes, estudiantes y egresados). (Sobre la democracia y el sistema políticoelectoral en Cuba nos hemos extendido en López Velasco 2017).

\section{La proyección internacional del socialismo latinoamericano del siglo XXI}

En este siglo A. Latina vio nacer tres organismos capaces de prolongar los esfuerzos de construcción del socialismo del siglo XXI en la esfera internacional: el ALBA, UNASUR y CELAC. El ALBA (Alianza Bolivariana para los Pueblos de Nuestra América) está hoy constituida por Cuba, Venezuela, Bolivia, Nicaragua, Dominica, Ecuador, Granada, San Vicente y Granadinas, Santa Lucía, Surinam, San Cristóbal y Nieves, y Antigua y Barbuda. A su vez UNASUR (Unión de Naciones de América del Sur) y CELAC (Confederación de Estados Latinoamericanos y Caribeños)

\begin{tabular}{|l|l|l|l|l|}
\hline Q Povista Dialectus & Ano 4 & n. 10 & Janeiro - Julho 2017 & p. 10-23 \\
\hline
\end{tabular}


pretenden ser, resepectivamente, alianzas de Estados de Suramérica y de A. Latina y el Caribe, sin presencia de los EEUU ni Canadá (a diferencia de lo que sucede en la OEA), capaces incluso (por lo menos en UNASUR) de implementar políticas comunes de defensa. Auspiciados por una y otra iniciativa germinaron espacios de cooperación que pretenden escapar a la lógica capitalista, como lo son el Banco del Sur (fundamental para apoyar proyectos de economía solidaria, que podrían crecer enormemente si a él fueran transferidas las reservas monetarias latinoamericanas hoy depositadas y al servicio en/de EEUU y la Unión Europea) y Telesur, esa gran alternativa informativa y cultural de Latinoamérica (extendida hoy a varias partes del mundo). Mas ese movimiento hacia la constitución real de una Patria Grande signada por la democracia socialista y la cooperación pacífica y solidaria, con voz propia en el escenario mundial pues libre de toda sumisión a cualquier imperio, está en 2017 en franco retroceso, a causa de las involuciones neoliberales observadas en Paraguay, Argentina y Brasil (y las vacilaciones del gobierno uruguayo). El futuro dirá si se improndrá ese retroceso o si vendrá otra oleada de democracia socialista, más democrática y más socialista, con numerosos canales de democracia directa y otros de democracia participativa, para reducir a su mínimo indispensanble las instancias representativas.

\section{Bibliografía}

Anónimo (2013). Pour en finir avec la démocratie directe, in "Contrepoints", in www.contrepoints.org/2013/12/02148136-pour-en-finir-avec-la-democratie-directe

Constitución Política del Estado, Bolivia, 2009, en Internet.

Constitución de la República del Ecuador, septiembre 2008, en Internet.

Daniel, Emmanuel (2012). Oui, la Suisse est la meilleure démocratie d'Europe, in www.slate.fr/story/62981/suisse-meilleure-democratie-europe

Guanche, Julio César (2017). La participación ciudadana en el Estado cubano, recibido vía e-mail en mayo de 2017.

Harnecker, Marta (2007). Gobiernos comunitarios. Transformando el Estado desde abajo: experiencia en la construcción del poder popular en el Municipio Libertador (Estado de Carabobo, Venezuela), Ed. Monte Ávila, Caracas.

López Velasco, Sirio (2016). Problemas y desafíos económicos del socialismo en la A. Latina del siglo XXI: Cuba, Venezuela, Ecuador y Bolivia, in América Latina en Movimiento, www.alainet.org Quito, Ecuador.

\begin{tabular}{|l|l|l|l|l|}
\hline Q Ronista Dialectus & Ano 4 & n. 10 & Janeiro - Julho 2017 & p. 10-23 \\
\hline
\end{tabular}


... . . (2017). La Constitución y el sistema político en Cuba y la búsqueda de una nueva democracia socialista en el siglo XXI, in América Latina en Movimiento, www.alainet.org Quito, Ecuador.

Sprich, R. (2017). La votation populaire est très ancrée dans les moeurs helvétiques mais, depuis une vingtaine d'années, son instrumentalisation par les populistes a relancé la réflexion sur ses limites, in L'Express, 05/04/2017, in www.lexpress.fr

\begin{tabular}{|c|c|c|c|c|}
\hline Qovista Dialectus & Ano 4 & n. 10 & Janeiro - Julho 2017 & p. $10-23$ \\
\hline
\end{tabular}

